\title{
Determination of THe Simulation Parameters OF THE WAXES USED IN INVESTMENT CASTING
}

\author{
Irena Kubelková, Aleš Herman \& Ondřej Vrátný
}
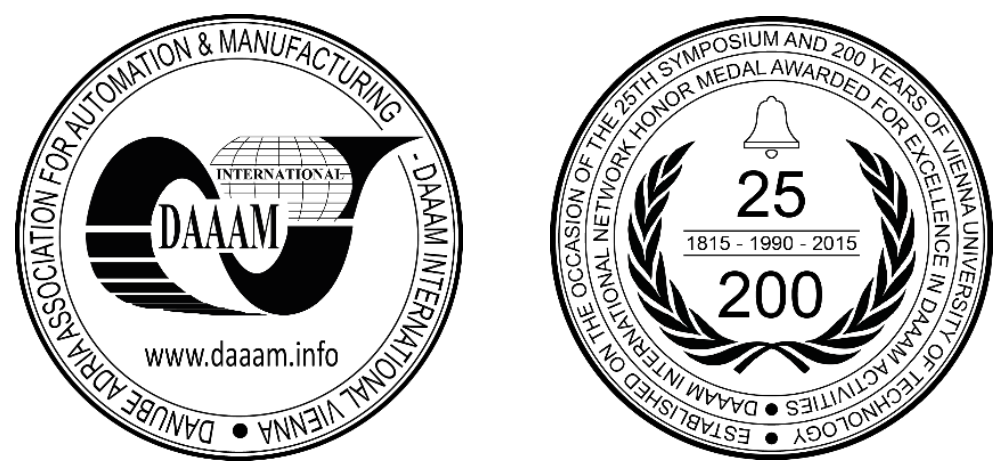

This Publication has to be referred as: Kubelkova, I[rena]; Herman, A[les] \& Vratny, O[ndrej] (2018). Determination of the Simulation Parameters of the Waxes used in Investment Casting, Proceedings of the 29th DAAAM International Symposium, pp.1222-1230, B. Katalinic (Ed.), Published by DAAAM International, ISBN 978-3-902734-20-4, ISSN 1726-9679, Vienna, Austria

DOI: $10.2507 / 29$ th.daaam.proceedings. 177

\begin{abstract}
Nowadays, when the requirements for the production of investment castings are increasingly high, it is necessary to accurately predict and remove defects from the process of casting the metal itself, but also during the production of wax blades. Accuracy and especially the ability to predict defects is key to this production. This paper deals with the current theme of wax mix properties for blade injection simulation. One of the main parameters of a properly executed simulation is to enter the correct initial parameters. For this reason, this article explores the properties of wax mixtures and their subsequent implementation in the process of simulating the blade injection process.
\end{abstract}

Keywords: Viscoelastic Properties; Investment Casting; Wax Pattern; Blades; Injection Simulation Process

\section{Introduction}

This article can be divided into several experimental sub-parts, the individual results are linked to each other and are the basis for the evaluation of the following experiments and measurements.

\subsection{Viscoelastic properties}

The main objective of this chapter was to determine the viscoelastic properties of wax mixtures - REMET HYFILL 478 model mix and REMET HYFILL $478 \mathrm{R}$ reconstituted wax in order to import these parameters into the wax blade injection simulation program. Individual experiments led to the detection of viscoelastic properties of wax mixtures. These experiments include measuring the strength characteristics of waxes (mechanical properties), rheological properties, determination of specific heat capacity, determination of specific thermal conductivity, comparison of viscosity of waxes, and investigation of changes in the volume of waxes in relation to temperature.

\subsection{Manufacturing of wax pattern blades}

The aim of this part was to design and verify the production technology of the blade with length $400 \mathrm{~mm}$. Dimensional requirements for blade casting are $\pm 0,25 \mathrm{~mm}$ for length tolerance and $\pm 0,5^{\circ}$ for rotation It was important to map all the critical locations that could affect the future quality of the blades and bring inaccuracies into the simulation. 


\subsection{Simulation results compared to measured values}

To measure 3D dimensions, the blade models that were the most different at the time of removal were deliberately chosen. Shovel A was easily removed in 27 seconds, and blade B then with great difficulty in 76 seconds. The reason for this selection is the basic assumption that dimensional stability in the wax modeling process affects the removal of the blades from the mold. During this operation, the blades are unstable, soft and therefore easily deformed

\section{Viscoelastic Properties}

Two types of waxes were used for the following tests:

- Green wax Remet Hyfill B-478 (virgine wax - green)

- Brown wax Remet RF-1 B-478 (reconstituted wax)

These are the waxes that are actually used for the manufacture of the studied blades.

\subsection{Rheology properties of wax mixtures}

The goal of the measurement was to determine the rheological properties of wax samples. The measured temperature range for both samples was $55^{\circ} \mathrm{C}$ to $72^{\circ} \mathrm{C}$. The actual measurements were performed in two consecutive steps, in which the shear rate was first raised from minimum to maximum set value (up) and subsequently decreased backwards. The shear rate range was chosen from $5 \mathrm{~s}-1$ (minimum adjustable) to $1000 \mathrm{~s}-1$ (1200 s-1). At each step, 30 (40) measurements were made in a linear step, one point being measured for $15 \mathrm{~s}$ (20 s).

Measurements were made first for green wax at $70^{\circ} \mathrm{C}$. In this first experiment, it was found that the wax exhibits rheological behavior that can be described by the Ostwald-de Waele model

$$
\tau=\mathrm{K} \gamma^{\mathrm{n}}
$$

The flow index value was close to 1 , which led to the choice of the linear step when changing the shear deformation velocity for the individual shear rate measured values. Measurement at $70^{\circ} \mathrm{C}\left(72^{\circ} \mathrm{C}\right)$ was repeated several times. Subsequent measurements were made for lower temperatures and a sample of brown wax was then measured.

Figure 1 shows the temperature dependence of the flow index of the two measured samples. As is evident, the value varies considerably, especially at temperatures up to $65^{\circ} \mathrm{C}$. At temperatures between $55^{\circ} \mathrm{C}$ and $65^{\circ} \mathrm{C}$ there is obviously a change in the structure of the material.

A graphical representation of the temperature-consistency coefficient for both samples is shown in Figure 2. Usually, this dependency can be described by an exponential relationship. However, as can be seen from the chart, exponential dependence does not match the measured data for both samples. This may be due to a change in sample pattern that occurs at temperatures around $60^{\circ} \mathrm{C}$.

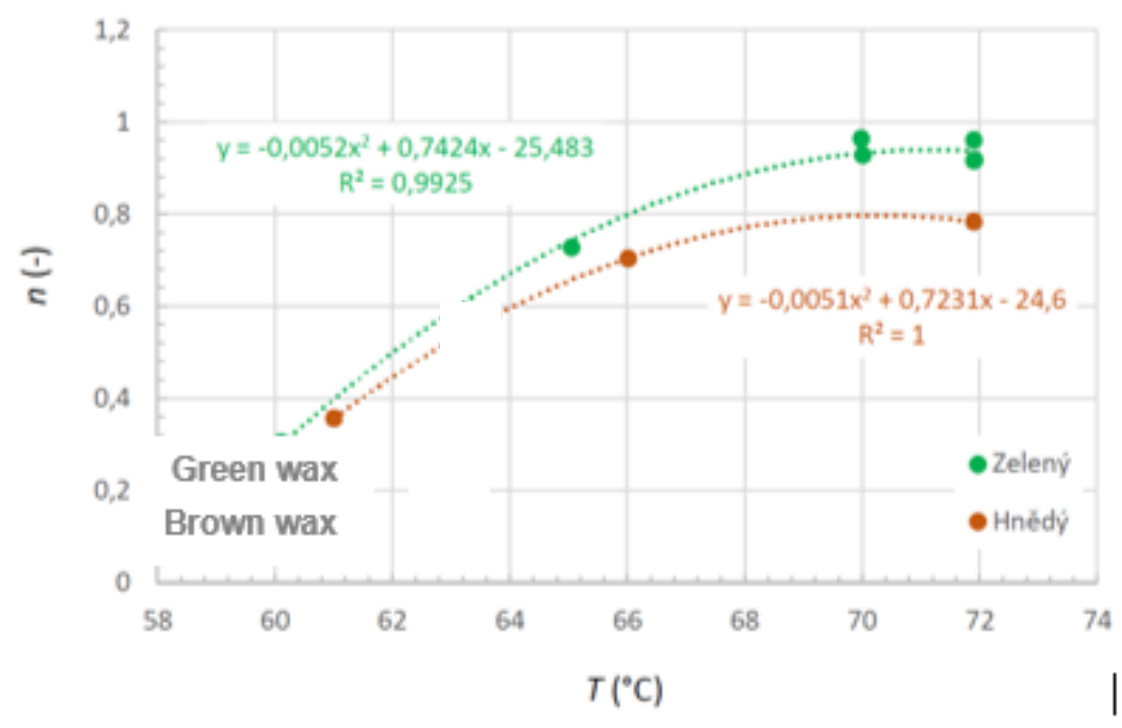

Fig. 1. Dependence of flow index of both samples on temperature 


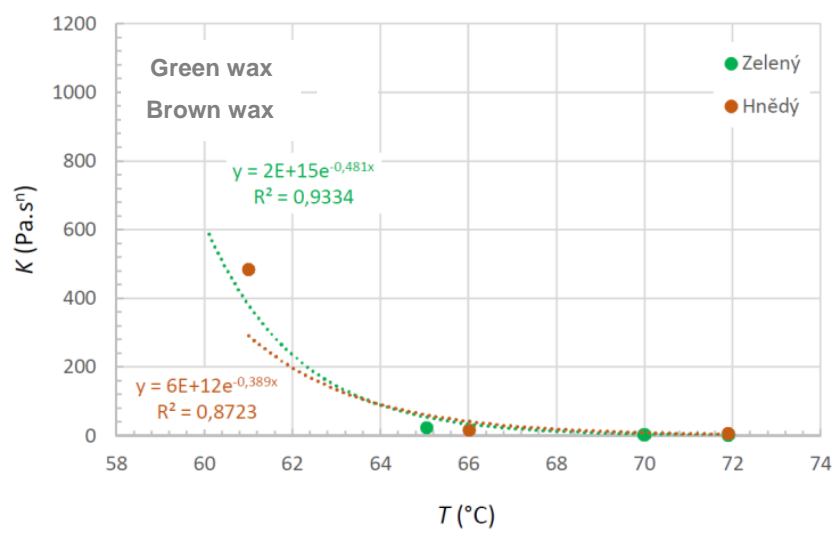

Fig. 2. Dependence of coefficient of consistency of both samples on temperature

\subsection{Determination of specific thermal capacity of waxes}

The object of the solution was to determine experimentally the specific heat capacity in relation to temperature. The specific heat capacity was measured by measuring the total heat flux, which was integrated and enthalpy determined. DSC Diamond differential scanning calorimeter (Perkin Elmer) was used for this measurement. The sample was then placed in a measuring aluminum capsule (nominal volume $40 \mu \mathrm{l}$ ) and sealed (sample weight was about 10-20 mg). Before sampling, the sample was heated to $90^{\circ} \mathrm{C}$ for about 20 seconds to melt the sample in the capsule to achieve good contact of the sample with the capsule wall. This was followed by a measurement of $2{ }^{\circ} \mathrm{C}$ to $100^{\circ} \mathrm{C}$ with a duration of 1 minute at the initial and final temperature at $10^{\circ} \mathrm{C} /$ minute. This procedure was repeated for each type of wax 5 times each time with a new sample.

In figure. 3 and 4 shows the course of the specific heat capacity at a temperature in the range of about $5^{\circ} \mathrm{C}$ to $100^{\circ}$ C. Here is a peak characterizing the phase shift from solid to liquid phase - wax melting. Here we see an increase in the specific heat capacity, which reaches in the region of the main peak approximately $4.3 \mathrm{~J} . \mathrm{g}-1 . \mathrm{K}-1$ at a temperature of about $55.7^{\circ} \mathrm{C}$ for brown wax and about $58^{\circ} \mathrm{C}$ for green wax.

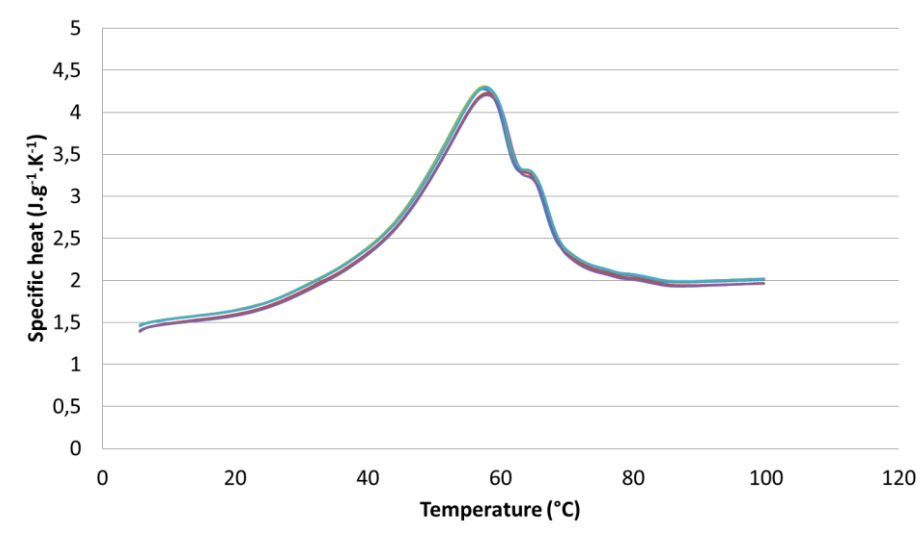

Fig. 3. Dependence of the specific heat capacity on the wax temperature - brown wax

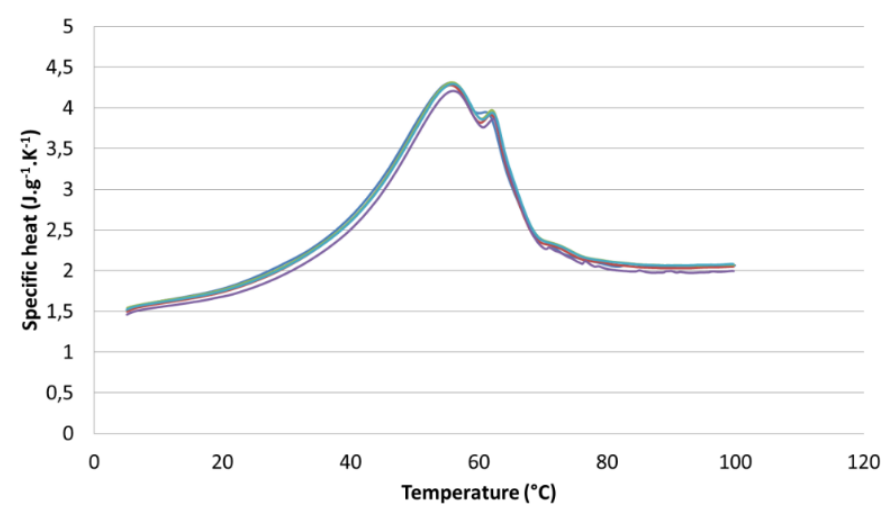

Fig. 4. Dependence of the specific heat capacity on the wax temperature - green wax 


\subsection{Thermal conductivity of wax samples}

The aim of the task was to measure the thermal conductivity of the delivered wax. To measure the thermal conductivity, an instrument was used which uses the principle of the hot wire for the measurement. The device adjusts the amount of electrical current passing through the resistance wire in the instrument probe

\begin{tabular}{|c|c|c|c|}
\hline \multirow{2}{*}{ Sample } & $\begin{array}{c}\text { Sample temperature } \\
{\left[{ }^{\circ} \mathbf{C}\right]}\end{array}$ & $\begin{array}{c}\text { Thermal conductivity } \boldsymbol{\lambda} \\
{[\mathbf{W} \cdot \mathbf{m}-\mathbf{1 . K}-\mathbf{1}]}\end{array}$ & Standard deviation \\
\hline \multirow{2}{*}{$\mathbf{1}$ - Green wax mixture } & $22^{\circ} \mathrm{C}$ & 0,1858 & 0,0037 \\
\cline { 2 - 4 } & $39^{\circ} \mathrm{C}$ & 0,1889 & 0,0069 \\
\hline \multirow{2}{*}{ - Brown wax mixture } & $22^{\circ} \mathrm{C}$ & 0,1935 & 0,0033 \\
\cline { 2 - 4 } & $39^{\circ} \mathrm{C}$ & 0,1951 & 0,0062 \\
\hline
\end{tabular}

Table 1 . The thermal conductivity of the samples

In the selected temperature range shown in Table 1, the thermal conductivity dependence on temperature cannot be statistically demonstrated.

\subsection{Dependence of changing the volume of waxes on the temperature}

The aim of the task was to determine the dependence of the change of the wax volume on temperature and pressure in two types of waxes. The individual waxes melted first and poured into a bowl where they hardened at room temperature for 24 hours. A bowl of molten and cold wax was placed in the glass cylinder on the base. When depositing, the flatness of the container was reduced due to the subsequent melting of the wax. $600 \mathrm{ml}$ of water was poured into the cylinder, the float was laid on the water level and the dial gauge reset.

Then the heating was switched on. Once the temperature was $40^{\circ} \mathrm{C}$, the temperature was maintained at this temperature for 2 hours as a result of heating the entire system. The experiment was terminated after $80^{\circ} \mathrm{C}$. On the figure 5 shows, that the volume change curve for green wax (virgin) is slower and does not achieve such large volume changes as is the case with brown wax (reconstituted). It follows that the higher quality of green wax has a significant effect on its bulk stability.

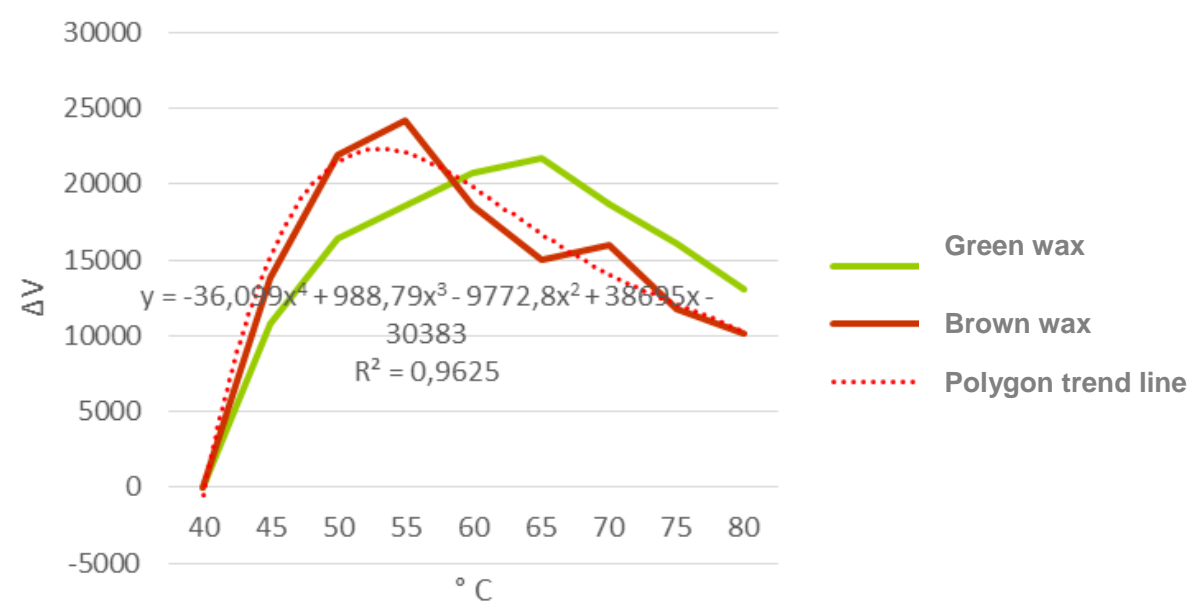

Fig. 5. Absolut change in system volume

\subsection{Comparison of wax viscosity}

The aim of the task was to compare the viscosity of two types of waxes. Table 2 and 3 shows significant differences of viscosity by ca. $60{ }^{\circ} \mathrm{C}$.

\begin{tabular}{|l|l|l|l|l|l|l|}
\hline $\mathbf{T}\left[{ }^{\circ} \mathbf{C}\right]$ & $\boldsymbol{\eta}[\mathbf{P a . s}]$ & $\mathbf{N}[-]$ & & $\mathbf{T}\left[{ }^{\circ} \mathbf{C}\right]$ & $\boldsymbol{\eta}[\mathbf{P a . s}]$ & $\mathbf{N}[-]$ \\
\cline { 1 - 2 } 60,1 & 1096,8 & 0,303 & 61 & 485,13 & 0,357 \\
\hline 65 & 23,16 & 0,728 & 66 & 16,32 & 0,704 \\
\hline 70 & 3,39 & 0,9465 & & 71,9 & 6,46 & 0,783 \\
\hline 71,9 & 2,92 & 0,9317 & & 71,9 & 2,92 & 0,9317 \\
\hline
\end{tabular}

Table 2. Green wax mixture

Table 3. Brown wax mixture 
The Figure 6 shows the difference in the curves of virgin wax (filled) and reconstituted wax. The difference between them is because of the worse quality reconstituted wax.

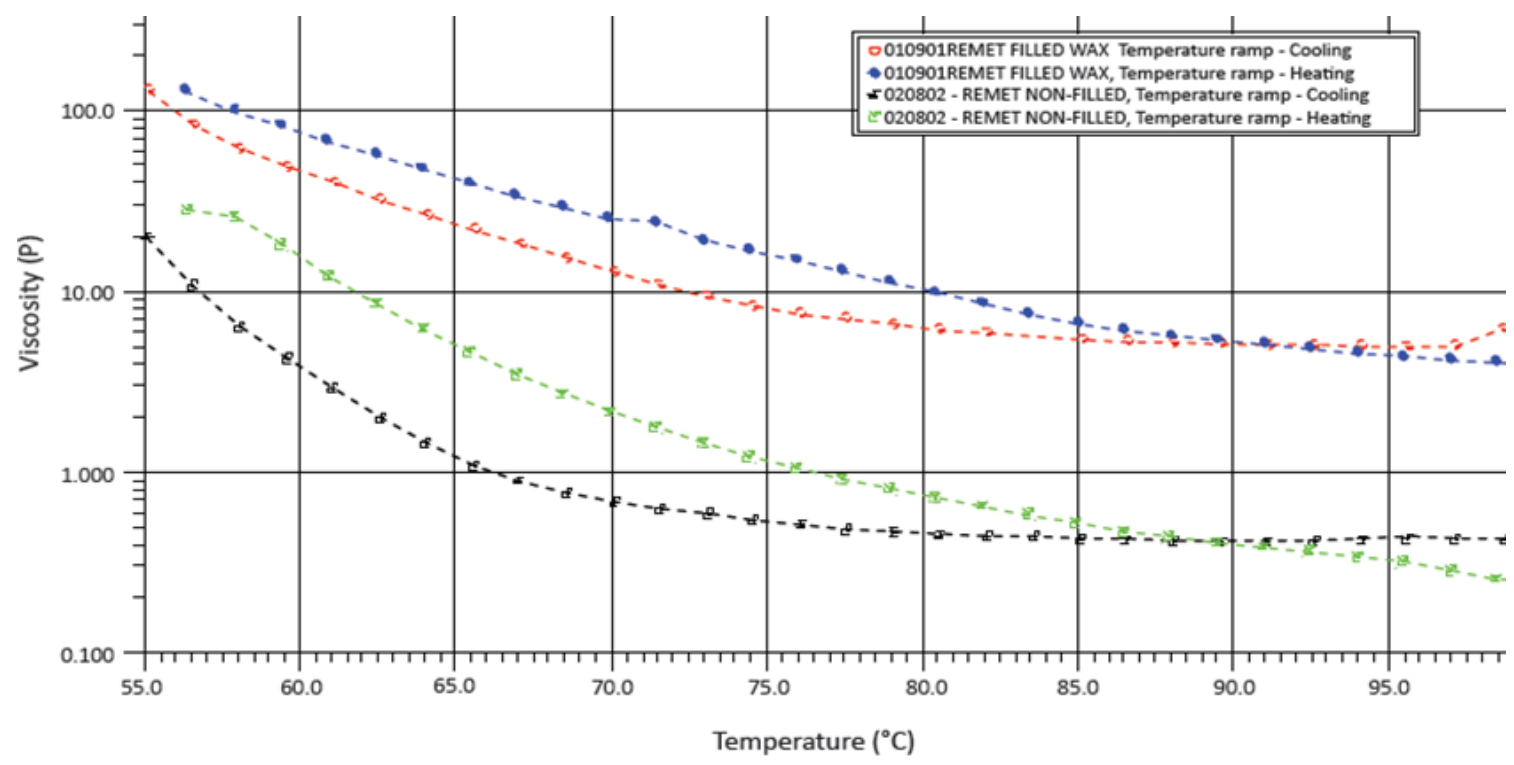

Fig. 6. Flow of temperature-dependent viscosity curves for brown and green wax

\section{Manufacturing of wax pattern blades}

In order to accurately simulate the blade injection process, it was necessary to record production times and to map the production of blade wax models and to identify all possible influencing factors. Based on the injection time, the working cycle of the blade was determined for 4 minutes (removal from the mold, removal of the inlet, insertion into the reformer, insertion into the water, starting the next injection, just before the next cycle, remove the reformer, remove the blade, to prepare the injection mold for the next paddle)

\subsection{Production cycle}

In particular, it is important to remove the blades from the injection mold, the times from removing the blade after immersing the reformer in the chilled water bath. It was set at between $10^{\circ} \mathrm{C}$ and $13^{\circ} \mathrm{C}$ with ice. During the experiment, additional pieces of ice were gradually added as needed. Water bath stamina has been defined on the spot according to the production cycle's needs, and with a view to the smooth flow of individual blades, ensuring maximum productivity and thus lowering production costs. Thus, the duration of the blade's stay in the water bath was set at 10 minutes, this time should be sufficient. The last recorded time was then the time since the reformer was removed from the water bath after the blade had settled into the preparation or the hinge. This time, however, should not be significant in view of ensuring dimensional stability. A total of 18 blades were produced in the test series.

\begin{tabular}{|l|l|}
\hline Activity & Parameter \\
\hline Blade injection time & $90 \mathrm{~s}$ \\
\hline Time of pressure endurance & $210 \mathrm{~s}$ \\
\hline Intensity of pressure & $3,4 \mathrm{MPa}$ \\
\hline Removal time & $49 \mathrm{~s}^{*}$ \\
\hline Time to draught & $74 \mathrm{~s}^{*}$ \\
\hline Endurance in a water bath & $600 \mathrm{~s}$ \\
\hline $\begin{array}{l}\text { Removal time from the reformer and lay } \\
\text { aside }\end{array}$ & $34 \mathrm{~s}^{*}$ \\
\hline Water temperature & $11,2^{\circ} \mathrm{C}^{*}$ \\
\hline Ambient temperature & $23,7^{\circ} \mathrm{C}^{*}$ \\
\hline
\end{tabular}

Table 4. Production cycle times and parameters / $*$ These values are the average values of all 18 measurements

One of the important partial conclusions can be found in the Figure 7, which shows the individual times recorded from the beginning of the top half mold exit to the blade removal itself. These times are very variable. The recommended time range is represented in the chart by blue horizontal lines. 


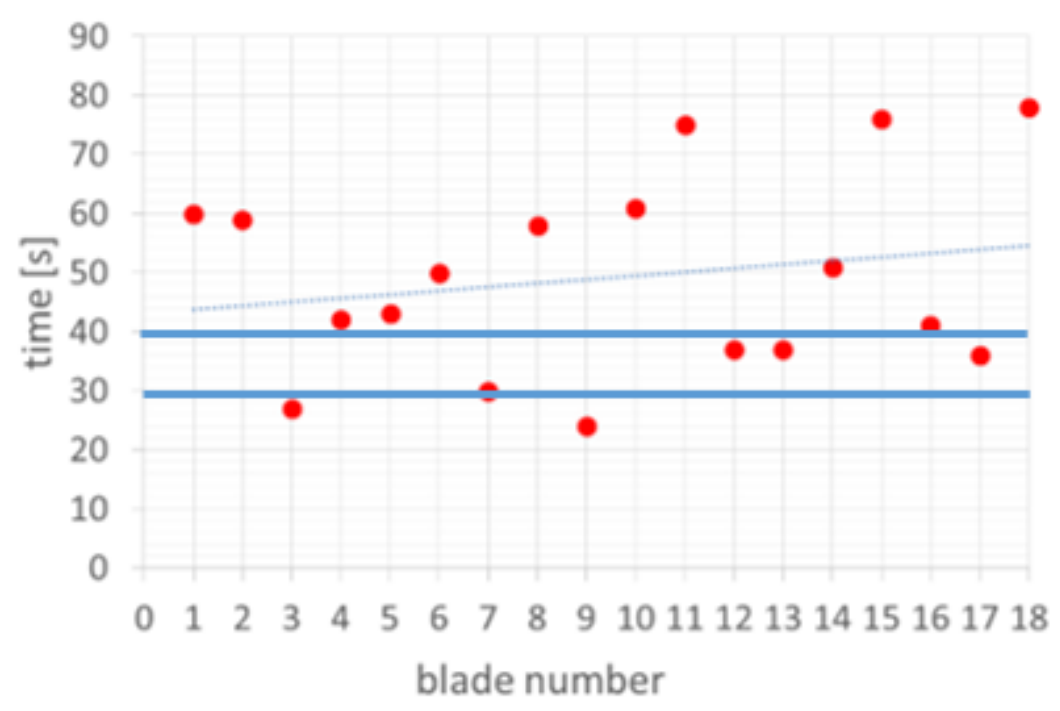

Fig. 7. Times from opening the mold after removing the entire blade

The main cause is inappropriate mold design. Figure 8 shows the problematic removal of the wax blade model. Because of that the mold should be made with auxiliary ejectors. These should ensure an easy and smooth removal of the just injected, dimensionally unstable wax model. This is a production section that has a very significant impact on the final dimensions of the wax model, so it cannot be neglected.

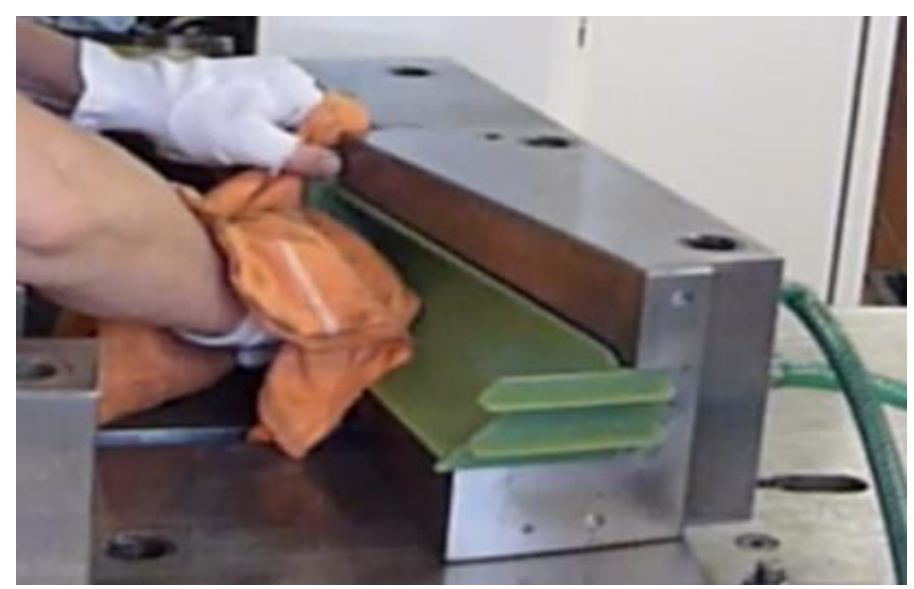

Fig. 8. Problematic removal from the mold

After the model is removed from the cooling bath immediately, its surface temperature is very low, up to around 13 ${ }^{\circ} \mathrm{C}$. The temperature is then increased and the temperature rises to ambient temperature. This is particularly noticeable on thin portions, such as a blade sheet. For the first two blades (from the left), it is noticeable that they have been chastened so thoroughly that the temperature equalization of the more massive areas, such as the lock part, lasts considerably longer and the temperature of the next 5 blades is between 21 and $22{ }^{\circ} \mathrm{C}$.

\subsection{Measurement 3-D}

Deliberately, the blades with the greatest differences in time were taken for $3 \mathrm{D}$ dimension measurement. The blade A was completely removed from the mold for 27 seconds. The blade B then with significant difficulty, since it did not unclip from the right mold part after opening for 76 seconds. The reason for choosing these blades is the basic assumption that dimensional stability in the wax modeling process mainly affects the removal of the blades from the mold. During this operation, the blades are unstable, soft and therefore easily deformed. For a larger overview of the following chapters, left-handed 3D scans are located in the left column of the blades $\mathrm{A}$, and in the right column there are $3 \mathrm{D}$ shots of the problem blade B. In figure 10 and figure 11 is the color difference between the dimensional results of the $3 \mathrm{D}$ scan and the dimensions of the CAD model. The following pictures are the variations of the wax model from the desired shape (defined by the CAD model). 


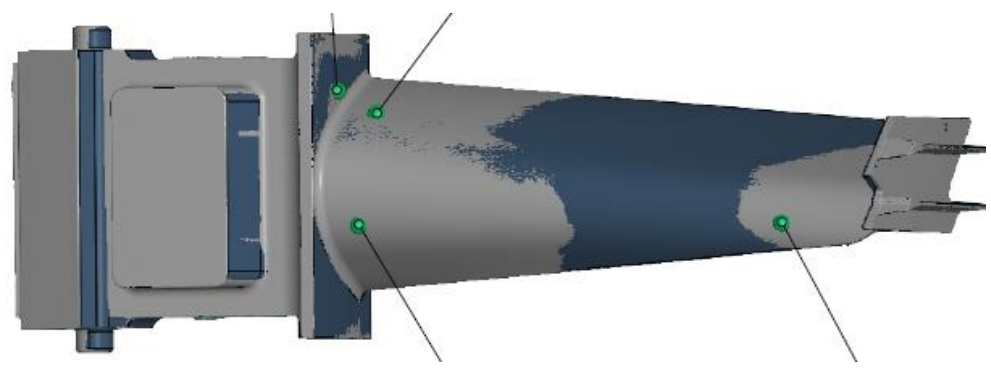

Fig. 9. Example Comparison of scan and CAD model for A (gray color - scan, blue color - CAD model)

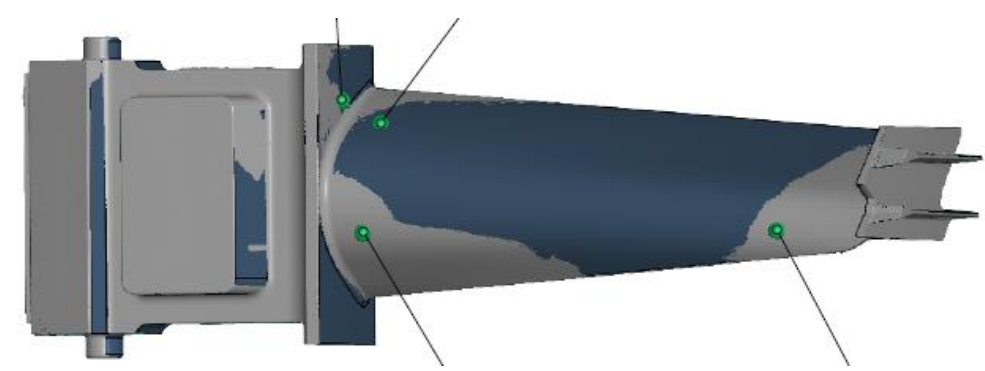

Fig. 10. Example Comparison of scan and CAD model for B (gray color - scan, blue color - CAD model)

By comparing the color maps to blades A on figure 12 and blade B on figure 13 it is obvious that the blade $\mathrm{A}$, which was removed from the mold without any difficulty, was much closer to the nominal dimensions than the blade B that had to be forcibly pulled out behind the lock area. The color scale expresses deviations from minus to plus $1 \mathrm{~mm}$. Green color is then the most accurate dimension.

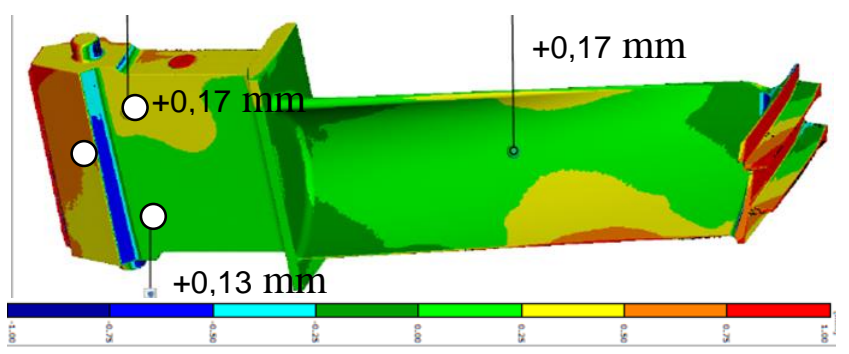

Fig. 11. Map of dimensional deviations of the blade A

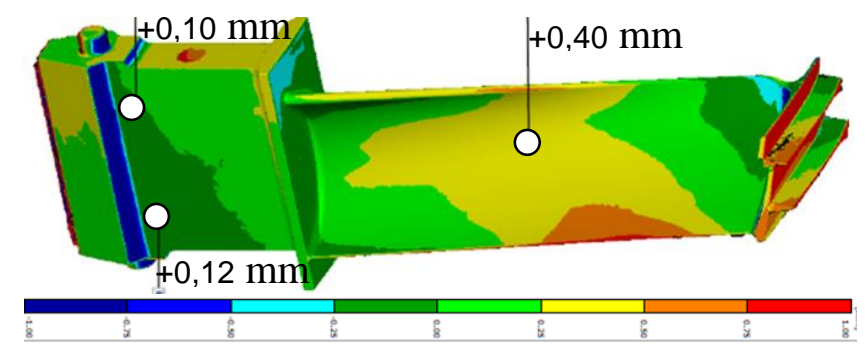

Fig. 12. Map of dimensional deviations of the blade B

The comparison leads to a totally unambiguous statement that the A blade is much closer to the desired size. Of the 30 evaluated RPS points, the deviation value is less than 1 in the case of blade B, all the other 29 values are smaller for the blade 3. The minimum deviation was $+0.00 \mathrm{~mm}$, maximum +0.58 in the case of Blade B.

\section{Simulation}

The task of the experiment was to compare the measured values with the simulation results. Simulation parameters were set to the same parameters as for real production, which are listed in table 4. The simulation was done in the Cadmould program. Already surface temperature on Figure 13 predicted the places where will be the deformation because of uneven amount of material. 

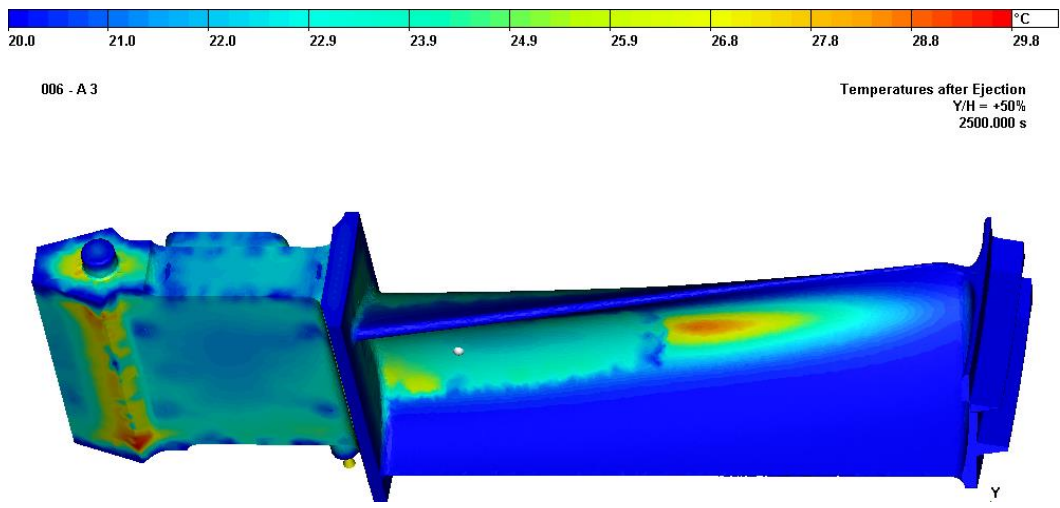

Fig. 13. Simulation result - surface temperature

A very beneficial result of the simulation was the prediction of the deformation of the blade, which subsequently confirmed the real measurement of the blade dimensions.
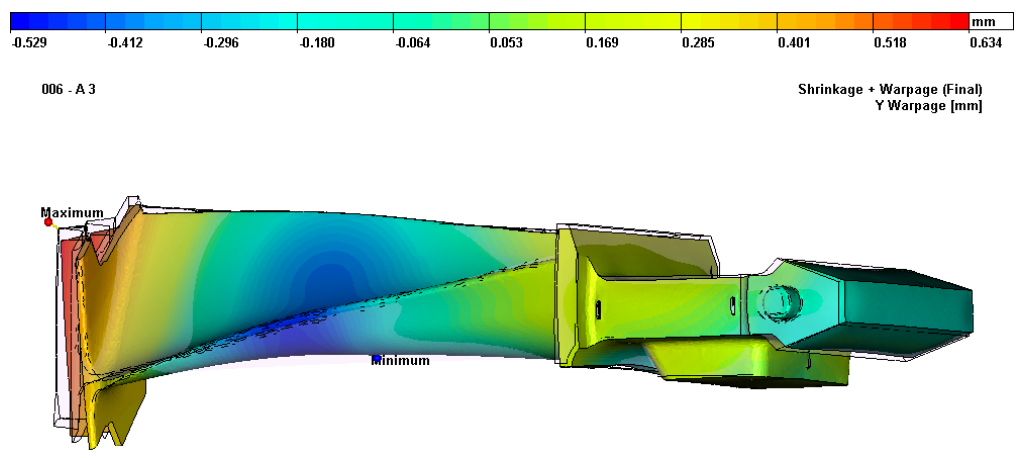

Fig. 14. Simulation result - deformation

Large deformations on Figure 14 occur in the central part of the blade leaf and then at the end of the blade. It is necessary to focus on these places in the future and prevent them by suitable cooling, by adding the ejectors to the mold (for easier removal without deformation) and, in particular, by a more suitable design of the reformer to ensure that the blade sheet is pre-deformed. Another problem that the simulation results have shown is closing the air in the blade lock and thus creating cold connections figure 15. For this purpose, it is necessary to focus on the production of the blade molding mold.

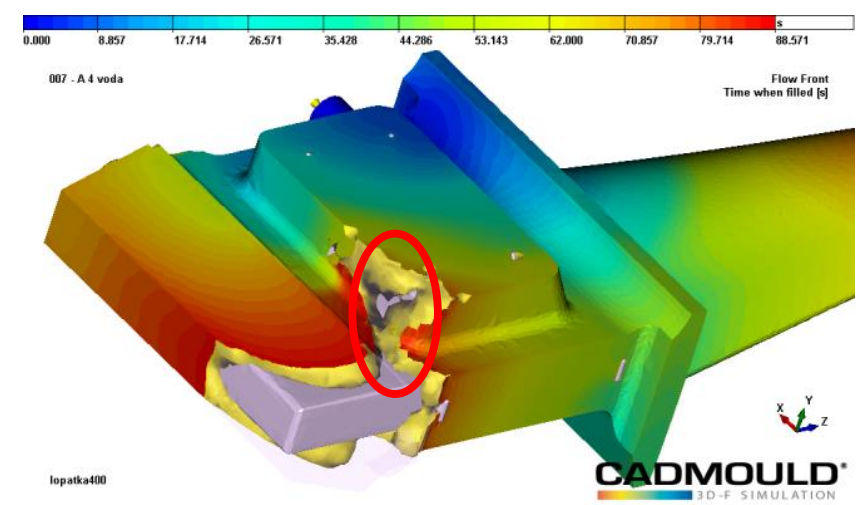

Fig. 15. Simulation result - closing air and cold connections

\section{Conclusion}

Based on the results of the measurement of wax samples it was possible to specify the input parameters of the simulation. It may be necessary to complete the tests performed on further refinement experiments to obtain more accurate values. It would be advisable to perform these tests on other types of waxes and then compare them, including their own blades. 
Conclusions to the actual blade production process are as follows. The removal of the blades from the injection molding should be stabilized in order to avoid the manipulation of the deformations. The 3D scans of the two selected blades clearly showed the problem of removing the blades from the mold

$3 \mathrm{D}$ scans have shown a problem with the blade length (the size of the deviation does not correspond to the CAD model of the cast - the model should be larger by about $1.5 \%$ - the alloy shrinkage, and the model is not even enlarged because the deviation of the upper band area is significantly larger than the blade deviation)

Until now, no consideration has been given to modifying the injection mold. It would be advisable to add it to the ejector plate. The recommended watering device for water temperature around $10^{\circ} \mathrm{C}$ should still be resolved with respect to repeatability. Large deformations occur in the central part of the blade leaf and then at the end of the blade. It is necessary to focus on these places in the future and prevent them by suitable cooling, by adding the ejectors to the mold (for easier removal without deformation) and, in particular, by a more suitable design of the reformer to ensure that the blade sheet is pre-deformed.

\section{Acknowledgements}

This report was created in cooperation with the company První brněnská strojírna Velká Bíteš, and in the form of an economic contract under the project TRIO No. FV10105, Research on the enhancement of the shape accuracy of wax models for turbocharger blade castings and strain gas turbines.

\section{References}

[1] Kubelkova, I.; Herman, A. \& Vratny, O. (2017). Evaluation of Critical Places on Wax Patterns of Blades, Proceedings of the 28th DAAAM International Symposium, pp.1126-1135, B. Katalinic (Ed.), Published by DAAAM International, ISBN 978-3-902734-11-2, ISSN 1726-9679, Vienna, Austria DOI: 10.2507/28th.daaam.proceedings. 157

[2] Dong, YW.; Zhao,Q.; Li, XI.; Li, XJ. \& Yang, J. (2017). Methodology to develop geometric modeling of accurate drilled cooling holes on turbine blades, proceedings of the ASME Turbo Expo: Turbine Technical Conference and Exposition, AMER Soc Mechanical Engineers, Three Park Avenue, New York, NY 10016-5990 USA, ISBN:9780-7918-5091-6

[3] Wang, D., He, B., Liu, S. et al. (2016) Dimensional shrinkage prediction based on displacement field in investment casting, The International Journal of Advanced Manufacturing Technology, Volume 85, Issue 1-4, pp 201-208: https://doi.org/10.1007/s00170-015-7836-1

[4] Teena, M., Manickavasagan A.: (2014) Thermal Infrared Imaging, Imaging with Electromagnetic Spectrum, pp 147-173.

[5] Wang, S.,Millogo J. D. H. (2011) Rapid prototype mold for wax patterns with the help of phase change materials, The international Journal of Advanced Manufacturing Technology, Volume 62, Issue 1-4, pp 35-41.

[6] Zhang S., Xu Z., Wang Z., (2016) Numerical modeling and simulation of water cooling-controlled solidification for aluminium alloy investment casting, The International Journal of Advanced Manufacturing Technology, Volume 91, Issue 1-4, pp 763-770.

[7] Rahimian M., Milenkovic S., Maestro L., et al. (2015) Physical Simulation of Investment Casting of Complex Shape Parts, Metallurgical and Materials Transactions A, Volume 46, Issue 5, pp 2227-2237.

[8] Raz, K[arel]; Zahalka, M[artin] \& Polak, R[oman] (2016). Injection Molding Simulations of Hardly Producible Parts from PBT, Proceedings of the 27th DAAAM International Symposium, pp.0501- 0505, B. Katalinic (Ed.), Published by DAAAM International, ISBN 978-3-902734-08-2, ISSN 1726-9679, Vienna, Austria DOI: $10.2507 / 27$ th.daaam.proceedings.075 